\title{
Teaching and Learning Mathematics around the City Supported by the Use of Digital Technology
}

\author{
Adi Nur Cahyono ${ }^{1^{*}}$, Matthias Ludwig ${ }^{2}$ \\ ${ }^{1}$ Department of Mathematics, Universitas Negeri Semarang, INDONESIA \\ ${ }^{2}$ Institute for Mathematics and Computer Science Education, Goethe-Universität Frankfurt, GERMANY
}

Received 11 January 2018 - Revised 24 July 2018 - Accepted 7 September 2018

\begin{abstract}
This study aims to explore the potential use of digital technology for supporting outdoor mathematics teaching and learning process. A study with explorative research approach were conducted in Indonesia. A portal and a mobile app for math trail program was created and several math trail tasks were designed around the city and uploaded into a system by the teachers. Then students run the activity by the help of mobile app to find and solve mathematical modelling tasks around the city. Data were gathered by means of participatory observation, interviews, questionnaires, and worksheets. The findings indicate that a meaningful digital technology-supported mathematical outdoor activity was successfully designed and implemented. The use of digital technology has the potential to support teachers in facilitating outdoor mathematics teaching and learning process. Students gained mathematical experiences and their performance in mathematics have improved. Further studies are essential for project development and implementation in other cities with different situation and different aspects of study.
\end{abstract}

Keywords: math trails, mobile learning, mathematical experiences, performance in mathematics

\section{INTRODUCTION}

Mathematics has an important role in daily and occupational life as a base for both science and society (Niss, 1994). It looks to be continually increasing in scope and density. However, its role is invisible to and unrecognized by the public (Relevance paradox, Niss, 1994). Behrends (2009) also stated that, currently, their understanding of mathematics remains unsatisfactory. They think that mathematics is not connected with interesting problems. There are very few who think of their mathematical school days with pleasure. TIMSS \& PIRLS International Study Centre reported that, internationally, only a few of students like learning mathematics (Mullis et al., 2012). Many students do not enjoy mathematical activities and appear unmotivated to learn mathematics. Whereas their attitudes affect their performance in mathematics (See Hattie, 2009). In Indonesia, only approximately $20 \%$ of eighth-grade students like learning mathematics (Mullis et al., 2012). Considering the Hattie's meta-analysis results, the above conditions have an impact on the low performance of Indonesian students. Indonesian students still rank low in international standardized tests. The Organisation for Economic Cooperation and Development (2018) reported that, in PISA 2015, the mathematics achievement of Indonesian 15-year students was ranked 63th out of 70 countries, with a score of 386 in comparison to an average score of 490.

These problems have led to think of ways to popularise mathematics in Indonesia. Through the MathCityMapProject carried out by the IDMI Goethe-University Frankfurt (Germany), the mobile math trail program has been developed and implemented in several places, including in Indonesia in cooperation with Universitas Negeri Semarang (Indonesia). This program is a program of math trails developed around the city that are supported by the use of digital technology, both for preparing the tasks through a portal and for doing math trail in the environment. The purpose of this research is to explore the potential of the use of digital technology for supporting

(C) 2019 by the authors; licensee Modestum Ltd., UK. This article is an open access article distributed under the terms and conditions of the Creative Commons Attribution License (http://creativecommons.org/licenses/by/4.0/). \adinurcahyono@mail.unnes.ac.id (*Correspondence) $\bigotimes$ ludwig@math.uni-frankfurt.de 


\section{Contribution of this paper to the literature}

- This study aims to explore the potential of the use of digital technology for supporting outdoor mathematics teaching and learning process.

- It integrates advanced digital technology with the math trails concept to illustrate the use of a technologically supported outdoor trail to enhance the teaching and learning of mathematics.

- The use of digital technology supported teachers in facilitating a meaningful mathematical outdoor activity. Students gained mathematical experiences and their performance in mathematics have improved.

mathematics teaching and learning process outside the classroom. The results of this study are then reported through this paper.

\section{THEORETICAL BACKGROUND}

This study is built within a theoretical framework informed by constructivist theory in mathematics education and underpinned by the concept of the math trail program and the use of digital technology to support the program.

Constructivists suggested that, in a learning process, learners should actively construct their own knowledge by linking new information acquired with prior knowledge, rather than just passively receiving perceptions or simply accept information transferred from others (Kant, 1922; Piaget, 1971). Although this process is individualistic (based on individual perceptions and reflections), but learner needs other people to create inter subjectivity so that his/her experiential world becomes stronger (Von Glasersfeld, 2006). The surrounding society and environment, which vary across cultures, can affect the development of an individual's cognitive skills (Vygotsky, 1978). This view also stressed the importance of student-teacher collaboration. Accordingly, it is necessary to organize learning environment accurately to enhance students' cognitive development. Here, teachers have an important role. The teacher should provide support to learners in constructing knowledge by organizing activities and providing artefacts that can mediate the process of knowing. Vygotsky (1978) defined this support as "scaffolding", a way to help a learner reach "the zone of proximal development", the distance between the actual developmental level and the potential development level.

In learning mathematics process, this support can be provided by teacher through the providing of mathematical tasks that provoke the expected learning (Brousseau, 1997) and offer guidance for students to reinvent the teaching matter in such interactions (Freudenthal, 1971). This method of teaching mathematics is built on the activity of interpreting and analysing mathematics. Accordingly, mathematics can be studied well through action, namely the action of organizing the subject matter, both matter from reality and mathematical matter (Mathematization, Freudenthal, 1968). Treffers (1987) extended Freudenthal's idea on mathematizing and distinguished it into two types: horizontal mathematization concerns the conversion of matter from reality into mathematical matter and vertical mathematization is related to the operation within a mathematical system.

Furthermore, The Organisation for Economic Cooperation and Development (1999) characterized mathematizing as having five aspects, namely: understanding a problem situated in reality; organizing the problem according to mathematical concepts; transforming the real problem into a mathematical problem that represents the situation; solving the mathematical problem; and making sense of the mathematical solution in terms of the real or authentic situation. Mathematization process can be experienced by students around them and not only in textbooks by taking mathematics outside the classroom. In this environment, learners can see the connection between mathematics and the real and natural world (Moss, 2009).

In many places around the world, there are special locations where mathematics can be experienced in everyday situations. Some mathematical tasks related to those locations can be designed by the teachers. Tasks located within an area can then be connected, so that a route connecting some task sites can be formed. Students can then explore mathematics in that environment by tracing a planned pathway that consists of a series of stops at which. This path is known as the math trail (English, Humble, \& Barnes, 2010; McDonald \& Watson, 2010; Shoaf et al., 2004). Math trail was first developed by Dudley Blane and his colleagues a math trail by blazing trails in the centre of Melbourne as a family holiday activity (Blane \& Clarke, 1984). The program was then strengthened when some schools took advantage of the trails by integrating them into their mathematics learning programs. The success of this idea allowed this program to be adapted and applied in different places, and math trail projects subsequently emerged in various cities, such as Vancouver, Boston, Philadelphia and San Francisco (Richardson, 2004).

Although the math trail project is not new, the idea of an outdoor education program supported by mobile technology appears to be new. This idea is facilitated by the fact that in recent years, developments in mobile technology and mobile phone use have improved significantly (Cisco, 2016; Lankshear \& Knobel, 2006). By taking advantage of the recent development of mobile technology, math trail tasks can be localized with GPS coordinates, pinned onto a digital map through a web portal and stored in a database. The trail walkers can then access the tasks 
and run the math trail activity with the help of a GPS-enabled mobile application. Mobile devices have the potential to integrate the characteristics of effective learning, such as situated realistic learning, motivational power and teamwork (Wijers et al., 2010).

Having outlined the background and theoretical framework for this study, we can clarify the research question as: How can the use of digital technology supports mathematics teaching and learning process outside the classroom?

\section{METHODS}

To address the 'how can' research question with regard to explore the potential of the use of digital technology for supporting mathematics teaching and learning process outside the classroom, this study used an explorative research approach. A portal and a mobile app were designed, with corresponding teaching and learning activities, several math trail tasks were designed, then a sequence of pilots was set up.

As a pilot study, this study was conducted in the city of Semarang, Indonesia, involving 520 eighth grade students and nine teachers from nine different junior high schools. The schools are representative of the Indonesian school situation, consisting of two types of location (urban and rural schools) and three levels of schools (high-, middle-, and low-level schools). This research was conducted in one introductory phase and three following phases (prototypical design, a small-scale field experiment, and a large-scale experiment).

In all pilots, researchers conducted observations as participating researchers by accompanying teachers and students in the activities. They made notes and collected data. Debriefing session was conducted afterward and individual mathematics pre- and post-test were also given before and after several activities. Data analysis began with the organization, annotation and description of the data for qualitative data analysis. For the quantitative analyses, data were collected from students in the empirical field studies.

\section{RESULT AND DISCUSSION}

Research has been conducted from 2014 to 2016. This research has begun with a preliminary phase in the first year of this study to define the specification procedure and develop technical requirements as a foundation and guideline in designing the prototypes. As explained in the theoretical background, the program was developed within a framework informed by constructivism in mathematics education and built using some basic concepts, such as the concept of the math trail and the use of mobile technology in mathematics education. Based on theoretical framework, in the next phase, the portal and mobile app were designed and the rule of the activity was formulated. The math trail tasks were created around the city by teachers. They were then validated and evaluated. Furthermore, the small-scale and large-scale field experiments consisted of an orientation session, a math trail run, and a debriefing session. A series of pilots were carried out in this phase. The results of the phases of this study are as follows.

\section{Result}

In the designing phase of the study, the portal has been designed. This portal is provided for uploading tasks created and embedded in a digital map. In this portal, the math trail route is created by connecting some tasks that have been added in the database in this portal. This portal is also equipped with guides and information about this mobile math trail project. GPS-enabled mobile application has been also designed in this phase. Figure 1 shows some of the interfaces of the app. 

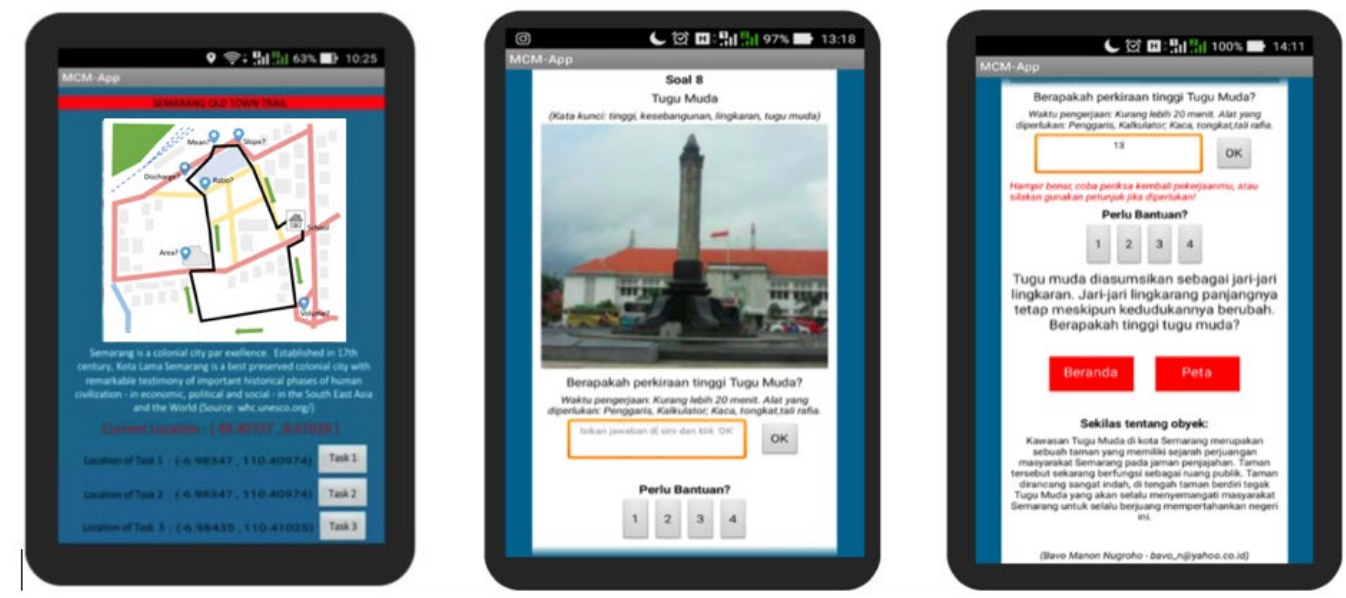

Figure 1. App interfaces
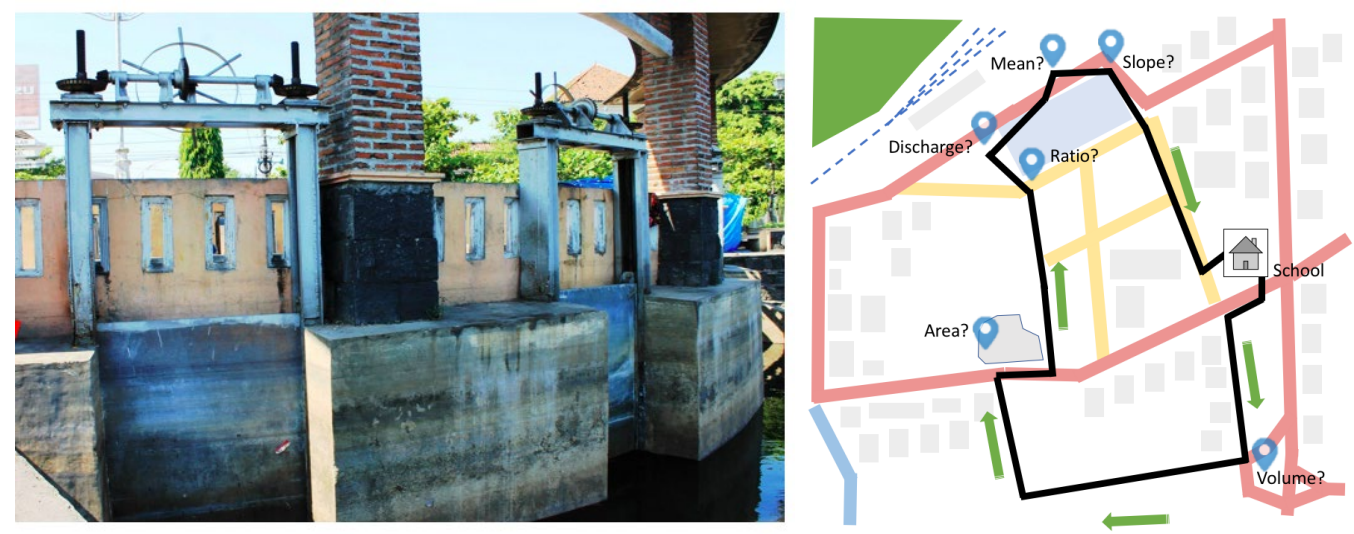

Figure 2. The task of the floodgates of Semarang Old Town in the Old Town Route

It is a native app that displays the math trail routes/map including location coordinate of the math trail tasks and user's current position and the authentic mathematical problems. The app informs them of the tools needed to solve the problems, the approximate length of the trail and the estimated duration of the journey. On the trail, the app, supported by GPS coordinates, helps the users to find the locations. Once on-site, the users can access the task, enter the answer, obtain feedback and ask for hints if needed. The app also give the brief information related to the object, such as: its history, its function, etc.

Beside the portal and the app, about 87 tasks grouped into 13 math trail routes scattered among various areas in the city of Semarang were also created by teachers through a teacher training and workshop. There are 6-8 tasks for each trail with varied topics located in a safe and comfortable environment. The trails were designed in several school areas, city parks, historical buildings, markets, tourist attractions, and other locations. Tasks are provided for all levels of secondary school, with varying difficulty. The topics also vary, such as geometry, statistics and probability, algebra and arithmetic.

Here is an example of the tasks, the task of the floodgates of Semarang Old Town in the Old Town Route. This task is about the sluice control in the Polder Semarang Tawang (Figure 2) that is related to the concept of ratios. The issues regarding this concept are simple; however, the topic becomes more attractive when the task is presented in a real case and adds important information related to the object. Tasks begin with a brief description of the object, so that the students also learn about their environment.

The problem reads as follows: "This polder functions to solve the flood problem around the Old Town. Suppose, with your city in an emergency, that you are asked to raise the floodgate one metre from its original position. How many times is a worm drive rotated to raise the sluice one metre from its original position?" Following the format of the task, we provide a hint on demand. The hint is as follows: "Note the comparison between the rotation of the worm drive, the three gears and the movement of the floodgates!". The math trails and the tasks were then uploaded into the portal. The math trail routes can be designed by connecting some of the tasks in the database on the portal taking into consideration the topic, level and location. A route contains between six and eight varied 


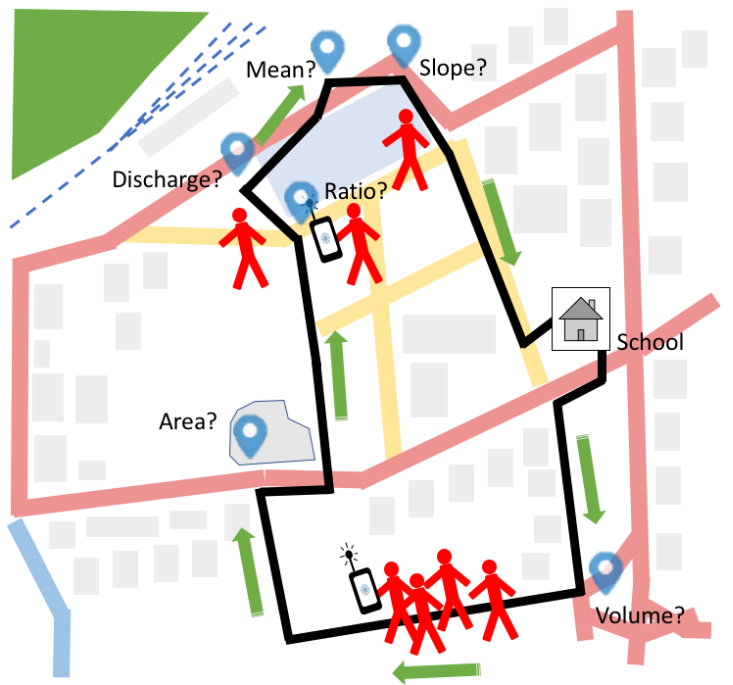

Figure 3. Illustration of the activity scenario

tasks. Some tasks and trails can be accessed by the public, and some are only accessible in private, with a special password.

One example of a route is Rute Kota Lama/the Route of the Old Town (See Figure 2), which consists of six tasks located in the Semarang Old Town area. These tasks are: the task on the volume of water in a pond; the task about the area of a church courtyard; the task on the sluice involving the concept of ratio; the task on the water discharge in a polder; the task on the average number of vehicles entering the parking area in one day; and the task on the slope of a ladder. Trail walkers need about two hours to explore a trail (about 1-2 km length) and solve the problems encountered along the path. Math trails tasks designed have passed the evaluation process, through validation by experts and simulation phase involved a small group of students and teachers and have been considered eligible for use in the next phase.

The large-scale field experimental phase was conducted in 2015 and 2016 involving 520 students and nine teachers from nine secondary schools. For each school, there were two classes (about 30 students/class) involved in this study, one class as the experimental group and one class as a control group. Both group at each school were taught by the same teacher with the same topic and subject matter, but with different interventions. In the experimental group, teaching and learning mathematics carried out by running the mobile app-supported math trail program for several times. Meanwhile, in the control group, students learned mathematics with the regular setting. In the mobile app-supported math trail program, students were divided into groups of 5-6 members. The activities were conducted during normal school hours about $2 \times 45$-minute periods beginning with the teachers giving a brief explanation of the rules and goals.

Groups then started their mathematical trip, each from a task location that was different from the others. As the groups trekked the trail, researchers and teachers observed and supervised students' activities but were not expected to assist them because all the necessary information was available in the app. With the help of the app, students in groups follow a planned route, discover task locations, and solve the problem on site, then move on to subsequent tasks. The scenario of this activity is illustrated in Figure 3.

Findings indicate that the activities ran smoothly, the portal and the app worked well, and the rules and goals of the program proved to be comprehensible. Teachers and students were enthusiastic about participating in the activities and gave a great deal of useful feedback. Teachers reported that they had been helped by the use of the digital technology to facilitate outdoor mathematics teaching and learning processes, both in the use of portals to prepare tasks for their students, as well as the extension of their guidance given to their students through the use of the mobile app. The teachers were more confident in teaching mathematics and increasingly enjoyed mathematics. Their mathematical beliefs changed significantly from being traditionally oriented to more inquiryoriented in all dimensions (Cahyono, 2018).

These teachers' beliefs have a positive impact on increasing students' intrinsic motivation to engage in activities. The open-ended questions resulted that $30 \%$ of students were delighted to engage in this activity because it was conducted outside the classroom, an unusual setting that offered comfortable conditions and it was a free and fun activity. The use of mobile devices for outdoor mathematics learning activities has become an attraction, encouraging $23 \%$ of students to engage in this activity. $18 \%$ reported that they learned how to apply mathematics in the real world. $16 \%$ liked collaborating, and $11 \%$ reported a different reason or did not give a reason. 


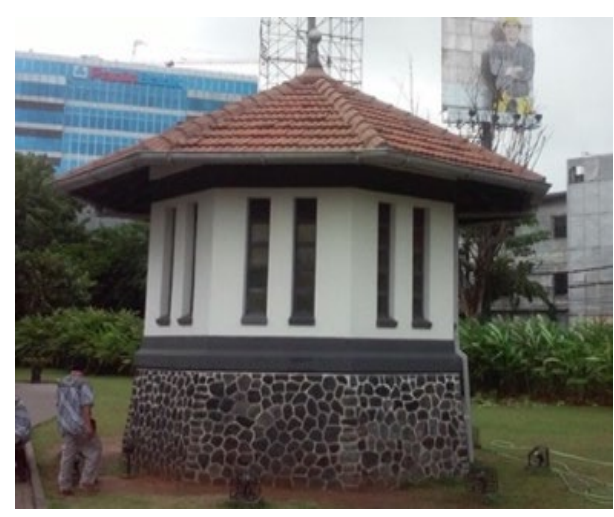

Figure 4. The Well Pump House

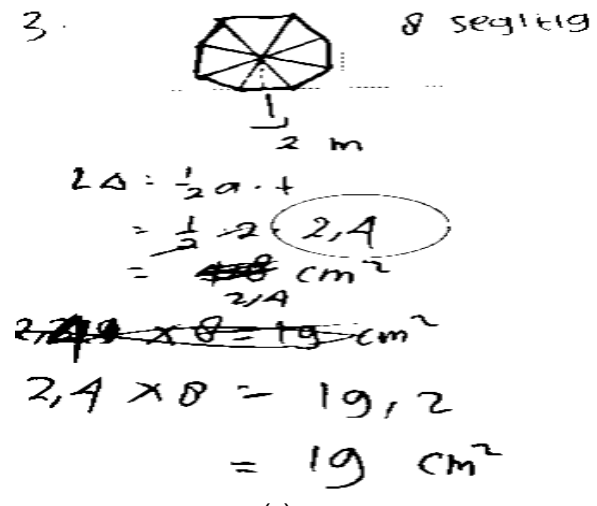

(a)
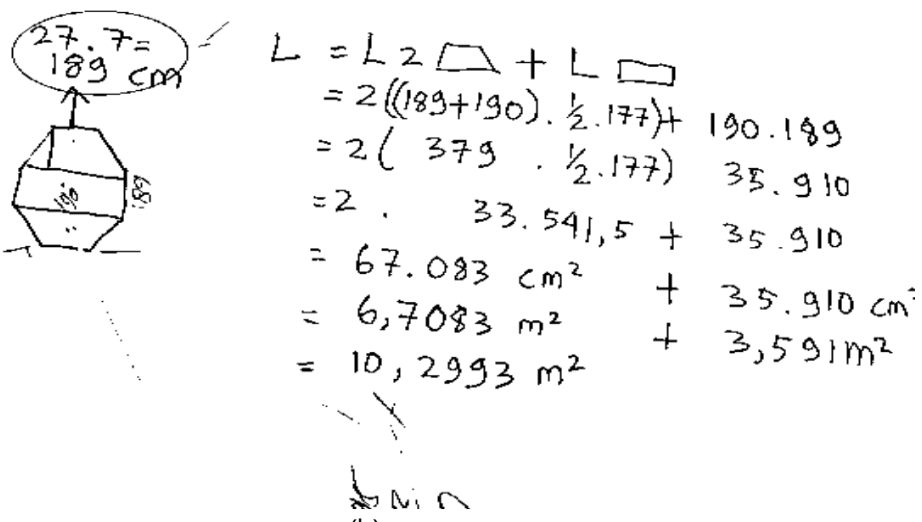

(b)

Figure 5. a) An example of student work on the Well Pump House task b) Another example of student work on the Well Pump House task

However, motivating is only as a stimulus for students to improve their engagement in mathematics. As a serious mathematics educational program, the main focus of this activity is to support students in learning mathematics and constructing their own mathematical knowledge. This program has been designed to offer students the opportunity to learn mathematics and construct their knowledge by practising the application of mathematics to solve real problems related to mathematics by following the stages of mathematizing.

To give example of the mathematizing process that was performed by the students in this program, here a result of student work in 'Well Pump House task' was given. This case concerns the Well Pump House task (see Figure 4), with the following task: "Estimate the area of the base of the building!" The surface of the base of the building is a regular octagon. The students had to measure the dimensions of the area outside the house because the door was locked. Figure 5a shows an example of students working on this task. The first group divided the base area (octagonal) into eight triangles.

The students' work shows that the group obtained the figure $t=2.4$. Observer (Pointing to ' $2 \mathrm{~m}$ ' on student work): "How did you get this?" Students: "We extended this wall using a rope, and then measured the distance between the rope and the middle of a wall on the side." The students' answer was correct; the area of the base of the building is $19 \mathrm{~cm}^{2}$.

The second group partitioned the base surface into several shapes, namely a rectangle and two trapezoids (Figure 5b). The strategy was correct, but the students made a measurement error. This error may have been made because the students were less careful measuring using a 27 -centimetre stick. The result was incorrect. However, the students learned from their activities, and more importantly, they also knew (from the feedback system) that their answer was incorrect and were able to look back to determine what error they had made.

This example provides some important information. First, although this question concerns area, the problem is unusual or non-routine. Second, the ways in which the students worked varied. Third, the application features helped the students to learn whether the answer was correct or incorrect. In this example, based on interviews, the students had to ascertain the wrong step, but based on their target, they had run out of time for this task and had to proceed to the location of the next task. "However, we knew what was wrong, and we already know how to solve that problem," said one member of the group. 
Previous findings indicate that the program has been carried out according to plan and has offered an opportunity for students to experience and learn mathematics by performing mathematization. However, the question arises as to whether the students' learning experiences in this program have an impact on their performance in mathematics. To answer this question, an individual paper-and-pencil post-test is given to students after they receive the interventions in this study. The test was given to students in the experimental classes and control classes. Similarly, to the purpose of the pre-test, the post-test was used to measure students' performance in mathematics, especially their ability and skills to understand and apply mathematics to solve problems. The results of pre-test vs. post-test of 272 students in the experimental group were: 63.01 vs. 79.28 (Mean); 11.73 vs. 9.22 (Std. dev.); 85.37 vs. 95.00 (Max.); 24.39 vs. 50.00 (Min.). The results of pre-test vs. post-test of 248 students in the control group were: 62.04 vs. 66.29 (Mean); 11.94 vs. 12.06 (Std. dev.); 90.00 vs. 95.00 (Max.); 32.50 vs. 35.00 (Min.).

Furthermore, to determine the effect of the intervention on students' performance in mathematics, a statistical comparison of the students' scores between the experimental and control classes was carried out. The t-test for independent samples grouped by condition (experimental and control classes) was employed. The results show that the mean gain of performance score of the 272 students in experimental group (16.2684) was significantly higher (Cohen's d=0.31) than the 248 students in control group (4.2540). This means that the students in the experimental group outperformed the control group. In other words, it shows that the intervention with the mobile app- supported math trail program has enhanced students' performance in mathematics.

\section{Discussion}

The mobile math trail program was carried out in the city of Semarang. The activities ran smoothly, the mobile app worked well, and the rules and goals of the program were comprehensible. The design and arrangement of the mobile math trail program have been successful in creating a pleasant situation and attractive environment offering valuable knowledge and experience in mathematics. Students embody the aspects of enjoying or being interested in the activity and the use of advanced mobile technology for learning mathematics and of value and meaningfulness of the mathematical tasks and the activity which were generated through the implementation of this program. By the help of digital technology, teachers play a role in setting up the problem and providing assistance to students in solving it. This condition is an expected part of the learning process (Brousseau, 1997). In line with Vygotsky's (1978) statement on the importance of scaffolding, in this program, digital technology has helped the process of providing support by the teacher to his students. This teacher's support has a positive impact on increasing students' engagement in the meaningful mathematical activities. Their engagement leads them to gain mathematical experiences and their performance in mathematics have improved. This corresponds to a Hattie (2009)'s statement: students' attitudes toward mathematics have an impact on their performance in mathematics.

Although this has shown success, there are some critiques that are important for this project and are useful for further development. Among them are the data show that the majority of students were interested in these activities because they were sited outdoors, one level above the use of digital technology. This is important point because one of the goals of this project is to develop the concept of a math trail by taking advantage of digital technology. Therefore, the potential of mobile technology to support outdoor mathematics learning needs to be more exploited in further development.

\section{CONCLUSION}

The study was successful in designing and offering an engaging mathematics educational program for students. The design of the program has been formulated in this study. A portal and a mobile phone app have also been designed through a designing process and have been considered eligible to be used in Indonesia. Several math trail tasks have been created by teachers. The result of empirical study shows that besides the learning arrangement, the teacher is also an important factor in the success of the implementation of the program designed in this project. The use of digital technology has the potential to support teachers in facilitating outdoor mathematics teaching and learning process. Students gained mathematical experiences and their performance in mathematics have improved. Further researches are essential for project development and implementation in other places with different situation and different aspects of study.

\section{REFERENCES}

Behrends, E. (2009). The year of mathematics in Germany. Gazette des Mathématiciens, 121, 101-106.

Blane, D. C., \& Clarke, D. (1984). A mathematics trail around the city of Melbourne. Monash: Monash Mathematics Education Centre, Monash University.

Cahyono, A. N. (2018). Learning Mathematics in a Mobile App-Supported Math Trail Environment. Cham (Switzerland): Springer International Publishing. 
Cisco. (2016). Cisco Visual Networking Index: Global Mobile Data Traffic Forecast Update, 2015-2020. Retrieved from http://www.cisco.com/c/en/us/solutions/collateral/service-provider/visual-networking-index-vni/ mobile-white-paper-c11-520862.pdf

English, L. D., Humble, S., \& Barnes, V. E. (2010, March). Trailblazers. Teaching Children Mathematics, 16(7), $402-409$.

Freudenthal, H. (1968). Why to teach mathematics as to be useful? Educational Studies in Mathematics, 1(1), 3-8. https:/ / doi.org/10.1007/BF00426224

Freudenthal, H. (1971). Geometry between the devil and the deep sea. Educational Studies in Mathematics, 3(3/4), 413-435. https:/ / doi.org/10.1007/BF00302305

Hattie, J. A. (2009). Visible learning: A synthesis of meta-analyses relating to achievement. London and New York: Routledge.

Kant, I. (1922). Critique of pure reason (2nd ed., revised). (F. M. Müller, Trans.) London: The Macmillan Company.

McDonald, S., \& Watson, A. (2010). What's in a task?: Generating rich mathematical activity. Oxford: QCDA.

Moss, M. (2009). Outdoor mathematical experiences: Constructivism, connections, and health. Mathematics Teacher Education, 4, 263-273. https:/ / doi.org/10.1007/978-0-387-09669-8_17

Mullis, I., Martin, M. O., Foy, P., \& Arora, A. (2012). TIMSS 2011 International results in mathematics. Chestnut Hill, MA, USA: TIMSS \& PIRLS International Study Center, Lynch School of Education, Boston College.

Niss, M. (1994). Mathematics in Society. In R. Biehler et al. (eds). Didactical of mathematics as a Scientific Discipline. Dordrecht: Kluwer Academic Publisher.

Piaget, J. (1971). Genetic epistemology. (E. Duckworth, Trans.) New York: The Norton Library.

Richardson, K. M. (2004, Augustus). Designing math trails for the elementary school. Teaching Children Mathematics, 11(1), 8-14.

Shoaf, M. M., Pollak, H., \& Schneider, J. (2004). Math trails. Lexington, MA: The Consortium for Mathematics and its Applications (COMAP).

The Organisation for Economic Cooperation and Development. (1999). Measuring student knowledge and skills: a new framework for assessment. Paris: Organisation for Economic Cooperation and Development.

Treffers, A. (1987). Three dimensions: A model of goal and theory description in mathematics: The Wiskobas Project. Dordrecht: Reidel.

Vygotsky, L. (1978). Mind in Society. Thedevelopment of Higher Psychological Processes. (M. Cole, V. John-Steiner, S. Scribner, \& E. Souberman, Eds.) London: Harvard University Press.

Wijers, M., Jonker, V., \& Drijvers, P. (2010). MobileMath: Exploring mathematics outside the classroom. ZDM Mathematics Education, 42, 789-799. https:/ / doi.org/10.1007/s11858-010-0276-3

\section{http://www.ejmste.com}

